\title{
Marcos Alves, de Fernando Pessoa: entre a psiquiatria e o desassossego
}

Cláudia Souza

Universidade Nova de Lisboa

s leituras sobre as ciências do psiquismo humano exerceram forte influência na escrita de Fernando Pessoa, podendo-se constatar os resquícios destas leituras em alguns projetos, comoé o caso do romance Marcos Alves.

Esse romance não se encontra nem organizado, nem finalizado (Teresa Rita Lopes foi a primeira a publicar fragmentos deste escrito pessoano em Pessoa por Conhecer).

O género literário deste escrito foi definido pelo próprio Pessoa, como podemos atestar na seguinte lista:

"ROMANCES: -

"Reacção" (protag. Miguel Calleya)

"Marcos Alves" (out of environment owing to Great moral sense).

1. is carried to TR.

2. goes mad.

3. commits suicide crushed by the evilness of the world around him."

[BNP/E3-48G-22r ${ }^{\mathrm{r}}$ ] 


\section{ROMANCES:-}

\section{"Reacção" (protag. M1guel Calleya)}
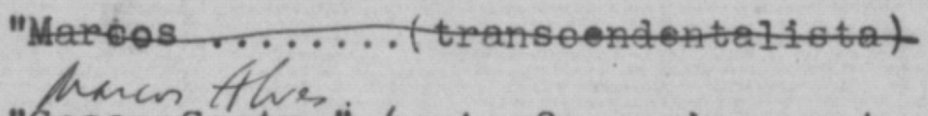

"Cesar environment owing to great moral sense).

1. is carried to Tr.

2. goes mad.

3. commits suicide crushed by the evilness of the world around $\mathrm{h} i \mathrm{~m}$. 
Essa lista, além de deixar evidente que Marcos Alves era um romance, também denuncia que, possivelmente, seria traduzido para o inglês. Esse não é o único documento no qual o autor deixa registrado que o texto Marcos Alves é um romance: no final do prólogo esse aspecto também é ressaltado:

\section{“Prologo}

«Uma cousa que ás vezes me tem dado que scismar - sabe o dr. Gomes -» disse o Sanches, chronista litterario do Diario da Manhã «é que tenha sido tão pouco estudado o lado subjectivo da loucura...»

"Que diabo quer você dizer com o lado subjectivo da loucura» perguntou bruscamente o medico.

«O... Olhe, quero dizer isto: vocês, os medicos, estudam as varias doenças mentaes, symptomas, manifestações, etcetera e tal, mas não tratam de averiguar o que diabo pensarão aquelles sujeitos lá em si, no que se não vê nos symptomas, voce comprehende bem. A psychiatria... a psychiatría... não sei bem como se diz.»

«Diga lá como quizér... adiante.»

«Vá lá... A psychiatría estuda-os por fóra, por assim dizer. Não quer saber do que o typo sente, lá elle propriamente syntomas á parte... Isso que me parece que seria interessante investigar... O diabo é que é difficil...»

«Para que diabo haviamos nós de querer saber o que os alienados pensam, lá por si, como voce diz? Isso não nos interessa... De resto, creia o meu amigo que não deve ser tão interessante como parece... Não ha propriamente um sentimento humanamente comprehensivel nos psychopathas... Ainda nos nevropathas, vá, mas nos psychopathas... Um... Não deve servir $\left[3^{v}\right]$ para literatura, se é por isso que você perguntou, e muito menos para poesia... Os reis Lears da vida pratica não são poeticos nem no que dizem nem no que fazem... O logar do enfermeiro de hospicio de alienados não serve como gradus ad parnassum... Ná... Basta o que se observa. Cural-os é que é o caso... Lá o que elles pensam, que raio de interesse pode isso ter? Não seja poeta fóra de 
horas, homem... Ora imagine voce... ora imagine... Voce conheceu algum... Sim, olhe, imagine voce que alguém ia escrever um romance sobre o que sentiria o Marcos Alves..."

[BNP $\left./ \mathrm{E} 3-27^{9} \mathrm{E}^{2}-3\right]$

Neste prólogo há o diálogo entre Dr. Gomes (possivelmente psiquiatra) e Sanches, um jornalista do "Diário da Manhã". Notase a crítica à psiquiatria, uma ciência que estudaria os doentes somente por fora, sem se preocupar com o que eles realmente pensam. Esta é a preocupação de Sanches, saber o que os doentes psiquiátricos pensam e o lado subjetivo da loucura. E o Dr. Gomes defende que o lado subjetivo da loucura não tem interesse para a literatura, para a ficção, que a subjetividade de um Rei Lear (referência a Shakespeare), na vida prática não teria o menor teor poético. Esse aspecto é extremamente relevante, pois a investigação pessoana sobre a loucura foi intensa e extensa como revelam os documentos do espólio. É interessante perceber que apesar do teor científico das leituras realizadas por Pessoa neste sentido, a sua preocupação com a subjetividade da loucura serviu justamente de matéria-prima para a sua criação literária. Pessoa fez arte com o seu medo da loucura. O romance Marcos Alves ressalta justamente esse fato, as leituras psiquiátricas encontramse presentes, como é o caso do documento citado e de um outro testemunho em que há referência explícita ao nome do Dr. KrafftEbbing, revelando o caráter alquímico dos escritos pessoanos que transforma muitas vezes ciência em ficção:

"O disfarced eKrafft-Ebbing (my preferred case).

O caso da creada do quarto de hotel; foge do hotel, mandando buscar as malas, pretextando mau serviço em carta; para Lxa , melhoria do correio. Encontra o comandante, casual com 3 (pintores) dos indivíduos que sabem do seu caso. Horror.

- A constatação de quanto maior importância lhe tinha ainda o facto sexual do que outro."

[BNP $\left./ \mathrm{E} 3-27^{9} \mathrm{E}^{2}-20^{\mathrm{r}}\right]$ 
O documento evidencia a influência do psiquismo humano para a estruturação do romance. A provável leitura de Krafft-Ebbing serviu para compor a escrita de Marcos Alves, evidenciando um certo padrão pessoano: o estreitamento dos limites entre a ciência e a ficção. Talvez a melhor explicação para esse fato seja a relação que Pessoa estabelece desde cedo com a verdade. E nesse ponto a escrita pessoana encontra-se em consonância com a filosofia nietzschiana, onde a noção de verdade é colocada em xeque e a verdade passa a ser analisada como mais uma faceta da ficção. Deixemos essa análise filosófica dos escritos pessoanos para outra oportunidade e voltemos a nos dedicar à relação entre os fragmentos do romance Marcos Alves e as ciências do psiquismo humano. Em outros testemunhos deste romance inacabado essa influência é ainda mais ostensiva, como é o caso do Epílogo:

\section{"Epílogo}

M[arcos]. A[Alves] (...). De 24 annos de edade, natural de Lisboa, (...)

Hereditariedade pesada do lado paterno; um tio morreu tuberculoso, a avó paterna soffre de alienação mental e na progenie do bisavo era essa senhora o unico filho que sobreviveu, havendo (...). Do lado materno nada parece haver de anormal.

M. era de um caracter extranho e infantil, fortemente laivado de idéas religiosas e d'um pudor (...). A sua vida sexual foi nulla, era indifferente (...)

Tentou suicidar-se duas vezes e à terceira tentativa foi bem succedido. M... mostrou nitidamente a evolução da paranoia de perseguição (some scientific, german, italian, etc. terms).

Do «Tratado de Doenças Mentaes» do dr. Florêncio Gomes, Parte III. cap.II."

[BNP $\left./ \mathrm{E} 3-27^{9} \mathrm{E}^{2}-20^{\mathrm{r}}\right]$ 


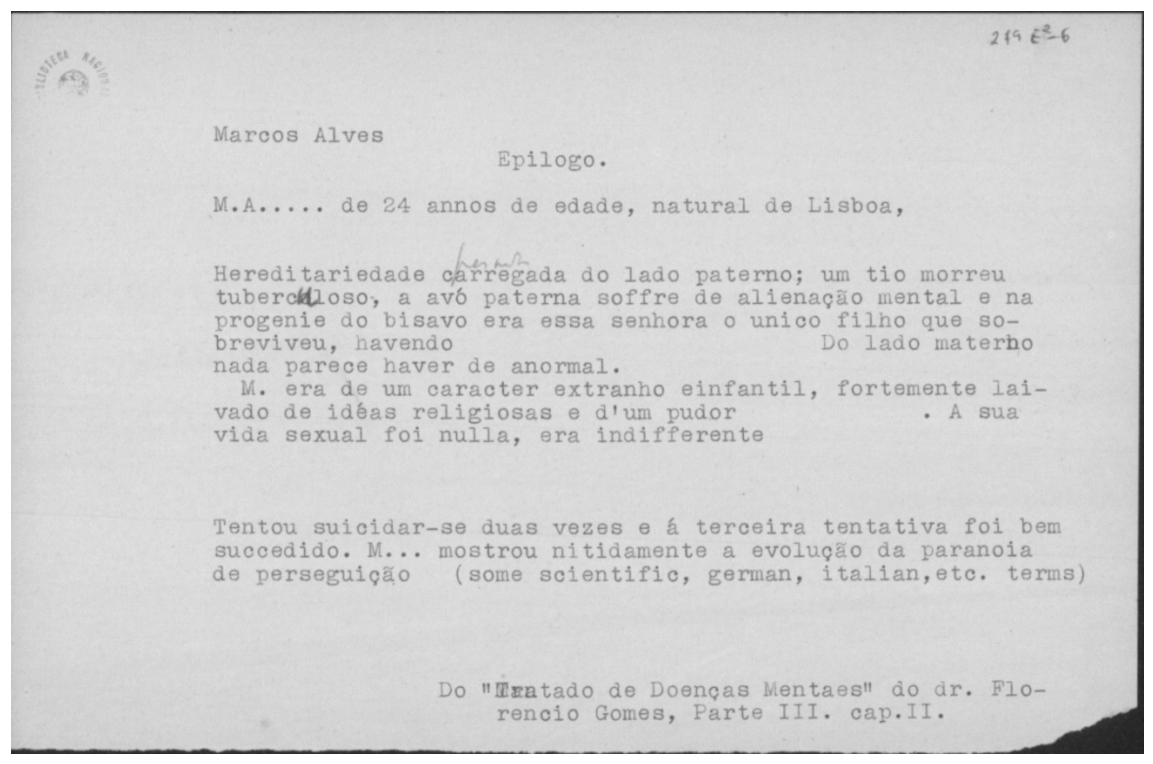

O primeiro aspecto que chama a atenção neste testemunho é a relação entre a ficção e a vida de Fernando Pessoa. A sua avó paterna Dionísia sofria de alienação mental assim como a avó de Marcos Alves. Esse texto foi publicado em Pessoa por Conhecer, numa secção intitulada "Autodiagnósticos na pessoa de outro", possivelmente pela proximidade entre esse texto e a biografia pessoana. Para além deste aspecto, a vida sexual de Pessoa era provavelmente nula até esse período. O namoro com Ofélia se inicia em 1920, data posterior a esse escrito. A sexualidade de Pessoa transformou-se em um tabu, muitos estudiosos têm-se debruçado sobre esse tema e, por isso, não é necessário aqui prolongar essa questão, de menor importância para esse trabalho. A questão da hereditariedade - patente neste escrito - dialoga com o texto do Dr. Arthur Leitão, citado neste trabalho, no qual o médico faz uma minuciosa análise da hereditariedade de João Franco para explicar o seu caso de loucura epilética. Outro ponto interessante deste escrito é a 
referência à paranoia. Trata-se de um tema recorrente nos textos pessoanos deste período pós-Durban. Todos os temas presentes e analisados neste fragmento nos mostram uma proximidade com a biografia pessoana e ao mesmo tempo uma distância da mesma. A possível explicação desse fato pode ser encontrada em um fragmento do projeto do desassossego:

"L. do D.

Escrever é esquecer. A literatura é a maneira mais agradavel de ignorar a vida. A musica embala, as artes visuais animam, as artes vivas (como a dança e o representar) entreteem. A primeira, porém, afasta-se da vida por fazer della um somno; as segundas, comtudo, não se afastam da vida - umas porque usam de formulas visíveis e portanto vitaes, outras porque vivem da mesma vida humana.

Não é esse o caso da literatura. Essa simula a vida. Um romance é a historia do que nunca foi, e um drama é um romance dado sem narrativa. Um poema é a expressão de idéas ou de sentimentos em linguagem que ninguém emprega, poisque ninguem falla em verso."

$\left[\mathrm{BNP} / \mathrm{E} 3-7-30^{\mathrm{r}}\right]$ 


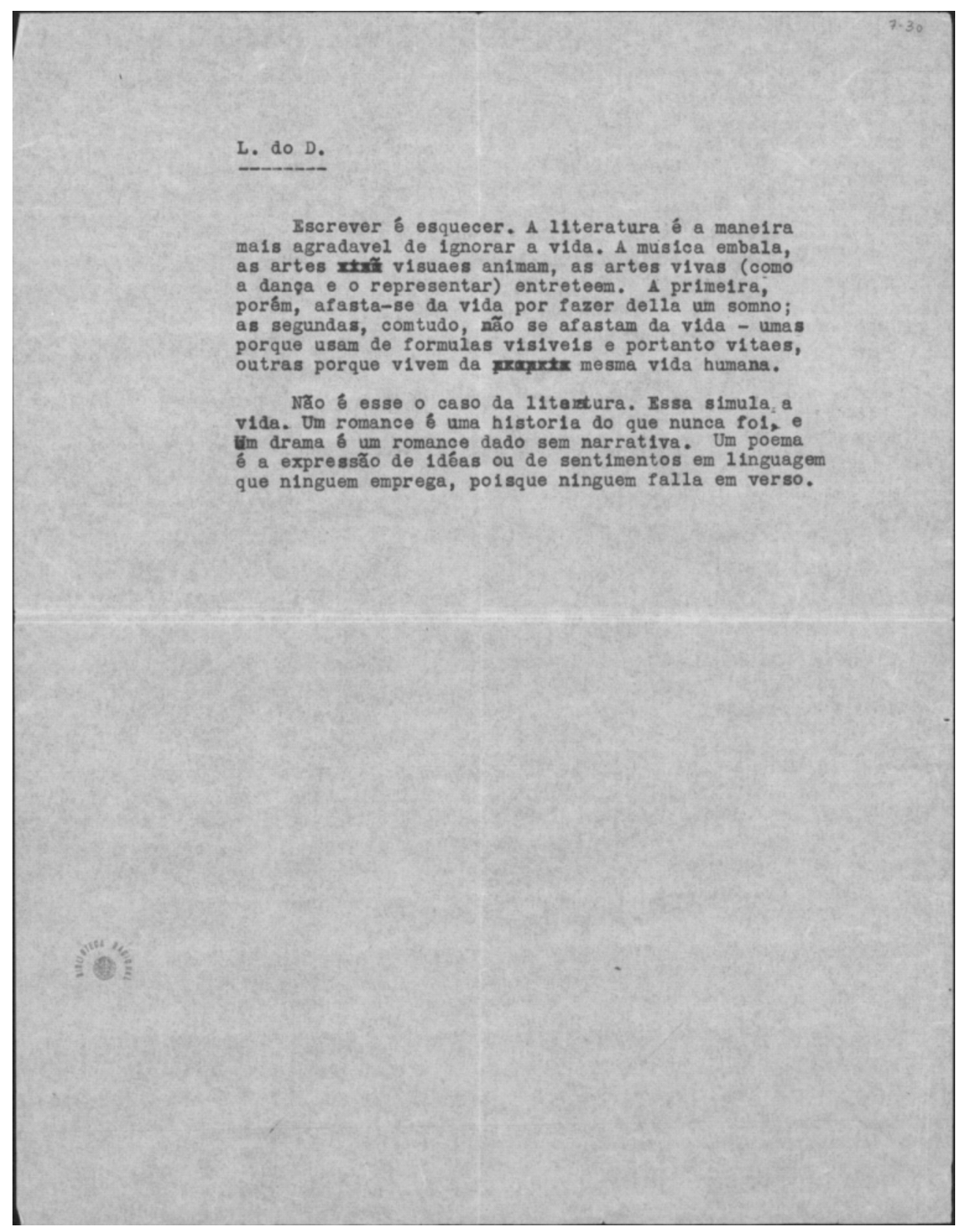


Utilizando esse fragmento como lente de leitura para o citado documento do romance Marcos Alves, podemos concluir que a escrita deste serviria para Pessoa esquecer, ignorar a vida e seus impasses e seus incómodos: nomeadamente a preocupação pessoana com a loucura e com o seu sentimento de inadaptação à vida. Transferir para o campo da ficção os seus pavores era um método terapêutico utilizado por Pessoa. Marcos Alves foi a história do que nunca foi: Pessoa nunca foi internado, nunca tentou o suicídio. Escrevendo esse romance o autor não apenas ignorou a face da vida que tanto temia, mas exorcizou os seus pavores. Em seu laboratório alquímico, Pessoa colocou seus medos no palco, levou-os até as últimas consequências, mantendo assim a sua vida parcialmente intacta.

O possível final deste romance é também muito importante, pois revela a identificação entre Marcos Alves e Antero de Quental:

"Fim.

Metteu o revólver na boca e estremeceu ao sentil-o frio contra o céu da boca. Mas lembrou-se, não sem prazer e orgulho, que assim se tinha suicidado Anthero de Quental. Tirou o revólver e manteve-o na mão, descahida esta sobre a colcha, ao longo da perna.

Passaram assim por elle instantes sem tempo, de vida ôca e neutra. Acordado para si, reparou de repente que o sol cessara, que tudo era côr de cinza, remoto, alheio, sem paladar para a vista.

Veio-lhe pela alma dentro o sentimento da inevitabilidade, da necessidade da morte. Era como se ella estivesse chegando, a hora, como um comboio, e ele simplesmente à espera. Uma ultima cousa qualquêr cahira-lhe da alma - já nem era lúcido. Parára-lhe o saber-se (...)

Tornou a metter o revolver na boca. D'esta vez sentiu o frio do canno d'encontro ao palato como quem sente uma cousa que não é nada, um pouco da cara d'encontro á mão. A apathia era absoluta. Tornara-se outro. Era uma cousa apagada. 
Faltava o gesto ultimo. Custou-lhe por ser simplesmente um gesto.

Tudo isto passou n'um minuto cheio de cinza de consciencia. Pouco a pouco ella foi morrendo em si.

Com o ultimo vêr dos olhos semicerrados viu só em torno a si uma bruma de vida...

Tudo era indeciso e sem forma.

Fechou os olhos e puxou o gatilho..."

$\left[\mathrm{BNP} / \mathrm{E} 3-27^{9} \mathrm{E}^{2}-42^{\mathrm{r}}\right]$

Pessoa foi leitor de Antero de Quental e mais do que isso: o autor português pensou em traduzir poemas de Antero. A relação entre Marcos Alves, protagonista deste romance, e Antero é complexa. Isso porque, se neste documento percebese uma forte identificação entre os dois, em outro documento [BNP $/ \mathrm{E} 3-27^{9} \mathrm{E}^{2}-18^{\mathrm{r}}$ ], Marcos Alves confessa que a leitura de Antero lhe faz mal. Antero conheceu Charcot e dele foi paciente. Sua doença nervosa foi diagnosticada como histeria masculina e nervosismo proteiforme. Neste ponto, encontramos harmonia entre Marcos Alves, Antero de Quental e Fernando Pessoa. No documento Pessoa afirma:

"Prefacio (aproveitar para o Shakespeare)

Não encontro difficuldade em defirnir-me: sou um temperamento feminino com uma intelligencia masculina. A minha sensibilidade e os movimentos que d'ella procedem, e é nisso que consiste(m) o temperamento e a sua expressão, são de mulher. As minhas faculdades, de relação - a intelligencia, e a vontade, que é uma intelligencia do impulso - são de homem.(...)"

[BNP / E3-20-17 $]$

Antero tinha também ambos os temperamentos, o diagnóstico de histeria masculina denuncia justamente esse fato. Na história da histeria, essa doença está intimamente ligada ao temperamento feminino. Pessoa, assim como Antero, se sentia dividido entre os 
temperamentos feminino e masculino. Marcos Alves também se identifica com Antero, um pouco antes de se suicidar, lembra "não sem prazer", que Antero se matou da mesma maneira. Nos minutos finais de sua vida, quando a decisão final precisa ser tomada, Marcos Alves lembra-se de Antero e a sua memória o recolhe como uma referência, e, dado o desfecho deste trecho, como um exemplo. Não foi a primeira vez que Marcos Alves tentou tirar a sua própria vida, mas só consegue executar o seu ato final, seguindo os passos de Antero, imitando os mesmos atos de Antero antes do seu suicídio. Esse aspecto ressalta novamente uma característica da literatura pessoana, aqui neste trabalho já ressaltada: a existência de tênues limites entre a realidade e a ficção. Parte da trágica e real história de Antero migra para a ficção pessoana, Marcos Alves, um romance inacabado, que migraria para outra ficção, Bernardo Soares, um possível autor deste texto. Soares é conhecido sobretudo pelo Livro do Desassossego, mas seus projetos estão para além deste. No espólio, Soares seria responsável por outros projetos, Marcos Alves entre eles (SOUZA, 2011). A seguinte lista, presente no espólio, confirma esse dado:

\section{"B. Soares}

1. Historia amorosa de um homem de genio.

2. Um chimico. (theatro, canção obscura)

3. O C. (...) s.

4. O Gramaphone.

5. O Caso Esteves (homem que casou por aparencia [...], interno num manicomio).

6. Um Portuguez (descendente de navegadores).

7. O Prior de Buarcos.

8. Marcos Alves.

9. O Orphão Absoluto (com o riso das senhoras).

10. Um doido.

Tachygraphia Contos - B. Soares." [BNP/E3-144G-29r] 
Essa lista, além de revelar que Bernardo Soares seria o possível autor do romance Marcos Alves, mostra que, mesmo após o surgimento dos heterônimos, (época na qual Pessoa se distancia das leituras inicialmente intensas sobre o funcionamento do psiquismo humano), o autor português ainda pensava em publicar alguns projetos relacionados a essas leituras, como é o caso de Marcos Alves, História de um homem de gênio, O caso Esteves e Um doido. Em outro documento encontramos uma relação direta entre Marcos Alves e o projeto do "desassossego":

\author{
"RReis - A doença do Christianismo \\ O sentimento apocalyptico da vida. (L. do D.) \\ Marcos Alves
}

A mulher. Necessidade nas democracias de educação para a vida de sociedade. Como crear a aristocracia de Tom: (1) A educação de tom, a insinuação do tom nas escolas; (2) a creação da atmosphera aristocratica, (3) a creação de riqueza (...)"

[BNP/E3-9-16

Fernando Pessoa tinha o hábito de escrever numa mesma folha de papel assuntos distintos, como parece ser o caso deste documento. O projeto de Ricardo Reis sobre o cristianismo apresenta relação com o projeto do "desassossego", Marcos Alves é escrito após um traço, o que pode significar uma separação entre esses projetos. Mas, há uma relação entre eles, por isso, Pessoa os escreveu na mesma folha e analisando o papel e a tinta, no mesmo momento. O sentimento apocalíptico da vida presente nos fragmentos do "desassossego", encontra-se também em Marcos Alves, como já constatamos neste trabalho. Há entre os dois projetos uma afinidade temática e estilística, fato que possivelmente fez com que Soares assinasse ambos. 
Revista do CESP-v. 32, n. 48-jul.-dez. 2012

$18 B / 245$

$9-16$

Prer - a doener a chano

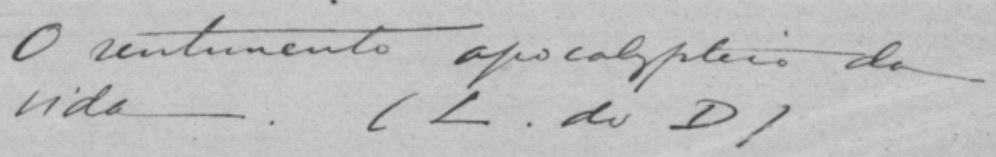

Mares Raveo

Af lenther. Necenise hes

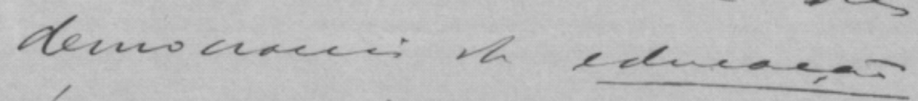

rava a uda da paie da ed.

Amo arar areitorace d

Ton: II) a colucacai de tom, a nisimacat do tom nes eriles;

ce/ a neacair da ateres/lhere aus-

tonativa, ( I) a nacar ce

rque

121 
Um outro documento deste romance, Cartas de Marcos Alves reforça esse sentimento apocalíptico diante da vida, tão marcante no "desassossego":

\section{"Cartas de Marcos Alves:}

Levei a vida toda a sentir-me inadaptado mesmo ás suas cousas mais altas e adaptar-me a todas, mesmo, ás mais reles. Assim criei uma dupla personalidade, da qual ambos os entes são falsos. Por isso me não encontro. Por detraz do homem de espirito e / um pouco de sociedade/, sou o artista morto, e não o sou realmente. Vendo o que quiz ser, o que me julguei plenamente capaz de ser, e attentando no que hoje irremediavelmente sou, uma angustia enorme, como a de ter perdido a alma, ou um céo, sobe-me á cabeça. Nunca me senti senão atravez de uma idéa de mim.

Tudo o que amei cedo ou tarde me veio a ferir Cortei todos os laços commigo proprio; hoje nada me amarra a mim a não ser o sentimento de dever estar amarrado. Só me sinto um ao attentar que sou, pelo menos, dois.

Pergunta-me v[ocê] como vim dar n'isto - n'isto de ser o cavaqueador brilhante, o triunphador das attenções... Perdendo-me. Cada pedra com que construi a m[inha] reputação de blagueur, de artista, de - tirei-as ao muro, hoje desgastado, com que me vedara / do não-eu/. Hoje não tenho alma. Vendi-a a mim próprio, a troco de moeda falsa, beijos comprados, amizades inuteis, admiradores despreziveis, inimigos que me esqueceram."

Esse trecho está em consonância com muitos fragmentos do Livro do Desassossego. A escrita de um sujeito "incompleto para a vida" e sem capacidade de ação está em plena harmonia com a escrita do "desassossego". Provavelmente, por esse motivo, Pessoa pensou em emprestar a sua caneta para Bernardo Soares assinar esse romance. Um fragmento do projeto do "desassossego" dialoga de forma muito próxima com as Cartas de Marcos Alves: 
“L. do D.

Tudo se me evapora. A minha vida inteira, as minha recordações, a minha imaginação e o que contém, a minha personalidade, tudo se me evapora. Continuamente sinto que fui outro, que senti outro, que pensei outro.

Aquillo a que assisto é um espectáculo com outro scenario. E aquillo a que assisto sou eu.

Encontro ás vezes, na confusão vulgar das minha gavetas literarias papeis escriptos por mim ha dez annos, ha quinze annos, ha mais annos talvez. E muitos d'elles me parecem de um extranho; desreconheço-me nelles. Houve quem os escrevesse, e fui eu. Senti-os eu, mas foi como que em outra vida, de que houvesse agora dispertado como de um somno alheio. (...)"

[BNP/E3-2-76r]

O desencontro consigo próprio é uma constante na escrita tanto de Marcos Alves quanto na de Bernardo Soares. O trecho do "desassossego" citado aqui pertence já aos escritos de Soares, é portanto posterior a 1929, quando o semi-heterónimo assume esse projeto. Essa inadaptação do indivíduo seja em relação à sua interioridade, seja em relação ao mundo exterior, muito marcante em Alves e Soares, é vivida de outra forma por Pessoa. $\mathrm{O}$ autor português poderia até se sentir um inadaptado, aturdido por nuances depressivas e suicidas como alguns dos seus outros eus. Mas, o que fica claro, principalmente a partir dos projetos aqui evidenciados, é um Pessoa muito ativo e militante, preocupado com sua época, com os aspectos políticos, sociais e estéticos do seu tempo. A inatividade fez parte (de forma paradoxal, pois escrever já é uma intervenção do artista em seu tempo) da vida de algumas das suas personalidades literárias e personagens de romance, contos: como é o caso de Marcos Alves (personagem de romance), de Bernardo Soares (semi-heterónimo), do Barão de Teive (personalidade literária). 


\section{Referências}

LOPES, Teresa Rita. O teatro do ser de Fernando Pessoa. Lisboa: Editorial Presença, 1995.

LOPES, Teresa Rita (Coord.). Pessoa Inédito. Lisboa: Livros Horizonte, 1993.

LOPES, Teresa Rita. Pessoa por Conhecer - Roteiro para uma Expedição. Volume I e II. Lisboa: Editora Estampa, 1990.

PESSOA, Fernando. Espólio. Biblioteca Nacional de Portugal.

PESSOA, Fernando. Escritos sobre Génio e Loucura. Edição de Jerónimo Pizarro. Lisboa: Imprensa Nacional Casa da Moeda, 2007. PESSOA, Fernando. Livro do Desasocego. Edição de Jerónimo Pizarro. Volume XII. Tomo I e II. Lisboa: Imprensa Nacional Casa da Moeda, 2010.

PESSOA, Fernando. Livro do Desassossego por Bernardo Soares. Prefácio e organização: Jacinto do Prado Coelho. Lisboa: Editora Ática, 1982.

PESSOA, Fernando. Livro do Desassossego por Vicente Guedes e Bernardo Soares. Volume I e II. Organização e notas de Teresa Sobral Cunha. Lisboa: Editorial Presença, 1990.

PESSOA, Fernando. Obras de António Mora. Edição de Luís Felipe Teixeira. Lisboa: Imprensa Nacional Casa da Moeda, 2002.

RIBEIRO, Nuno. Fernando Pessoa e Nietzsche: o pensamento da pluralidade. Lisboa: Editora Verbo, 2011.

SOUZA, Cláudia. Vicente Guedes e Bernardo Soares: para além do Desasocego. Cultura ENTRE Culturas, n. 3, Lisboa, Âncora Editora, 2011, p. 186-191. 


\section{Resumo}

Neste artigo pretendemos demonstrar, através da análise de documentos do espólio pessoano, as relações existentes entre o projeto Marcos Alves, romance pessoano inacabado, e as ciências do psiquismo humano a escrita do Livro do Desassossego.

\section{Abstract}

In this article we intend to show, through the analysis of the documents contained in the Pessoa Archive, the relations among the project Marcos Alves, a unfinished romance of Pessoa, and the sciences of the human psychism and the writing of the Book of Disquiet. 